Research Article

\title{
High-Quality Economic Development in Huaihe Economic Zone Level Measurement and Evaluation
}

\author{
Xin Sun, ${ }^{1}$ Shu Fang, ${ }^{1}$ and Su Zhang $\mathbb{D D}^{2}$ \\ ${ }^{1}$ School of Statistics and Applied Mathematics, Anhui University of Finance \& Economics, Bengbu 233030, China \\ ${ }^{2}$ Department of Physical Education, Anhui University of Finance and Economics, Bengbu 233030, China \\ Correspondence should be addressed to Su Zhang; zs0625@163.com
}

Received 6 December 2020; Revised 24 January 2021; Accepted 4 February 2021; Published 18 February 2021

Academic Editor: Hijaz Ahmad

Copyright (C) 2021 Xin Sun et al. This is an open access article distributed under the Creative Commons Attribution License, which permits unrestricted use, distribution, and reproduction in any medium, provided the original work is properly cited.

\begin{abstract}
This article constructs a comprehensive evaluation index system from four aspects: economic vitality, innovation efficiency, green development, and people's lives. Use the entropy method to comprehensively measure the urban competitiveness level of 25 counties and cities in the economic zone, clarify the differences in their high-quality development levels, and use spatial econometric analysis methods to study the spatial agglomeration and dispersion and spatial convergence of regional urban competitiveness. The results show that the following: (1) the overall high-quality development level of the Huaihe River EcoEconomic Zone is not high, and the overall time and space characteristics is "high in the east and low in the west"; (2) there is a positive spatial autonomy in urban competitiveness and the spatial distribution of the Huaihe River, and relevantly, the degree of closeness of spatial associations between cities is generally low; (3) the gap between the level of urban competitiveness in Jiangsu Province is shrinking, the development of other provinces has a time lag effect, and there are differences in the level of urban competitiveness. Finally, to promote the high-quality development of the Huaihe Economic Zone, we must follow the law of the basin and the characteristics of spatial distribution and implement targeted strategies.
\end{abstract}

\section{Introduction}

The report of the 19th National Congress of the Communist Party of China (CPC) pointed out that China's economy has changed from a high-speed growth stage to a high-quality development stage, and achieving high-quality development of China's economy is not only the demand of China's current national conditions but also the direction of better and faster development of the national economy in the future. As the fourth economic growth pole of China, the Huaihe River ecological economic belt, following the Yangtze River Delta, the Pearl River Delta, and the Bohai Sea, is bound to be an important area for China to achieve high-quality economic development. In 2018, the CPC Central Committee and the State Council promulgated the Development Plan for the Huaihe River ecological economic belt, which defined the implementation path of better and faster economic development in Anhui, Jiangsu, Shandong, Henan, and Hubei Provinces.
Urban development is an important embodiment of regional and even national economic development and an important force to promote social progress. Improving urban competitiveness is an important way to promote regional development. Compared with other cities, urban competitiveness refers to the actual and potential ability of a city to create and promote regional and national wealth. It is also the ability of a city to optimize the allocation of resources in its subordinate regions for its own development. Urban competitiveness is the ability of internal stability, sustainable development, external attraction, and radiation demonstrated by the urban system. And it is the ability of cities to exert their own advantages and create a good internal and external environment to gather, spread, and utilize various resource elements. The national and regional coordinated development strategy has been gradually improved, and the regional competition with the central city as the main driving force has become increasingly fierce. Make good use of transportation, 
platform, system, talents, and other resources so that the central city can truly play the pivotal role of driving the core of regional innovation and development, leading the direction of regional reform and development, gathering regional resources and moving lines, and accelerating regional high-quality development with the construction of high-energy central cities. Therefore, it is of great theoretical significance to take the urban agglomeration of Huaihe River ecological economic belt as the research object, grasp the connotation of high-quality development, and construct a scientific, complete, and reasonable evaluation system of high-quality development, so as to realize the high-quality economic development of five provinces.

At present, the country and the region have not issued a clear evaluation system of high-quality development measurement with a reference value. From the current research situation, foreign scholars pay attention to the mechanism of economic development quality and lack of in-depth research on the index system. Most domestic scholars pay attention to the problems and contradictions of high-quality development and the connotation and system of economic development, which is unscientific and limited to a certain extent. It is difficult to measure the development level of high-quality effectively. On the basis of analyzing the connotation of high quality and combining with the characteristics of urban agglomeration in Huaihe River ecological economic belt, this paper establishes a set of evaluation system of high-quality development of economic belt covering four aspects: economic vitality, innovation efficiency, green development, and people's life. The objective entropy method is adopted to calculate the weight coefficient and comprehensive scores of urban agglomeration in Huaihe River ecological economic belt from 2005 to 2018, and the multidimensional dynamic evaluation analysis is carried out. In order to achieve high-quality economic development in Huaihe River eco-economic belt, the competitiveness of its internal urban agglomeration should form a unified whole. Therefore, the spatial correlation is used to analyze the spatial agglomeration and dispersion characteristics of regional urban competitiveness, and the spatial convergence of urban competitiveness is empirically analyzed by the $\alpha$ an $d \beta$ convergence method. Finally, according to the analysis results, it provides practical suggestions for government departments to formulate relevant policies.

\section{Literature Review}

With regard to the research on urban competitiveness, foreign scholars started early in this field, and a large number of research results have emerged. Scholars explain the concept of urban competitiveness from the perspectives of market share, labor productivity, and production and consumption function. Lever and Turok [1] combined with the geographical constraints of the city itself and believed that the competitiveness of a city refers to "the ability of a city to provide products and services and meet the needs of regional, national, and international markets, while increasing actual income levels, improving the quality of life of citizens and promoting the city capacity for sustainable development." Malecki [2] absorbed the above ideas and created employment, attracting domestic and foreign investment and skilled migration and the ability to generate sufficient income as the connotation of urban competitiveness. Turok [3] defines urban competitiveness as the relative position of enterprises in a region in the external market, internal resources, and resource utilization. Iyer [4] et al. compared urban competitiveness with national competitiveness and emphasized that both are competing for market share. Gundersen [5] et al. studied the complex relationship between urban competitiveness, corporate positioning, and transportation systems and found that labor, land, capital, management, and technical skills are the main factors of urban attractiveness and competitiveness. Chinese scholars have lately studied urban competitiveness. Among them, Ning and Tang [6] et al. believe that urban competitiveness refers to the creation and maintenance of urban competitiveness under the combined effects of multiple factors such as society, economic structure, values, culture, and institutional policies. A city develops its ability to optimize the allocation of resources in its subordinate large areas, thereby achieving sustained growth in the city's economy. $\mathrm{Ni}$ [7] believed that if a city has greater advantages in competition and development compared with other cities, its ability to compete for, own, control, and transform resources and markets, improve residents' welfare, and create value must be stronger.

Foreign scholars have also made profound explanations on the mechanism of economic development quality. From the classical growth model, the neoclassical growth model, to the endogenous growth model, economics has been researching economic growth. The initial state of sustainable economic growth, the transformation from factor input to the study of total factor productivity and innovation, reflects. It has evolved from the quantity of economic growth to the study of the quality of economic growth. Krugman [8] believes that East Asia's economic growth mainly depends on factor inputs, and total factor productivity has no prominent effect on East Asia's economic growth. Mlachila [9] et al. believe that, for developing countries, more sustained socially friendly growth is high-quality growth. Qi [10] builds an economic growth quality evaluation system from the aspects of scale performance, structure, and coordination. Domestic scholar Li [11] believed that economic development includes not only the speed of economic growth and the efficiency of economic growth but also the coordination between economic structure and social structure and structure based on the related theories of traditional development economics. Chao [12] et al. constructed an economic growth quality index from the four dimensions of economic growth structure, stability, achievement distribution, and ecological environment. Regarding the construction of an indicator system for high-quality economic development, there are few foreign documents in this regard. Li [13] builds a city competitiveness evaluation system, from the perspective of urban 
agglomeration city competitiveness analysis and divides cities into competitive endogenous competition. In the two aspects of power and exogenous competitiveness, the main components are analyzed to analyze the competition chain network model of large-scale urban agglomerations in the Bay Area, to obtain sources of competitiveness in cities, and to propose strategies to improve urban competitiveness. In China, urban competitiveness is more often used to reflect the quality of economic development. Among them, Liu and Li [14] constructed urban competitiveness indicators from GDP, GDP per capita, and GDP growth rate and explored 30 cities in China for 22 years. Since the dynamic changes in urban competitiveness, the scope of this indicator is relatively narrow; Tian and Fang [15] have relatively complete measurement from the six indicators of economic agglomeration, spatial radiation, opening to the outside world, cultural innovation, social services, and ecological protection. In order to improve the competitiveness of the central cities in the Han River Basin, the urban competitiveness indicators have been further developed, but the dynamic effects of the development of urban competitiveness have not been considered; Yang and Li [16] outlined the transformation of urban competitiveness into urban sustainable competitiveness indicators, introducing spatial networks, and spillover effects have not been empirically tested; $\mathrm{He}$ [17] is a relatively novel measure of urban competitiveness from an ecological perspective, which is not universally applicable. In the latest research on urban competitiveness, Liu and Song [18] measured urban competitiveness based on economics and people's livelihood but lacked ecological measurement; Li [19] outlined that, from the perspective of "five in one," the level of urban development has been constructed more comprehensively, and the calculation panel is shorter.

Regarding the empirical research and methods of regional economic development quality, scholars have established various models, such as "maze," "pyramid," "bowstring arrow," "steering wheel," "urban value chain," and "flywheel." Rogerson [20] used Porter's diamond model in practice and concluded that corporate development strategies, urban core industry development, and urban development factors will affect the scale of urban competitiveness. Singhal [21] et al. used a hierarchical model to evaluate the competitiveness of several cities in the UK and started with the characteristics of circular economy, especially the strategy of improving the competitiveness of cities from the perspective of business development, and put forward suggestions for improving the competitiveness of cities. Jamali [22] et al. quantitatively evaluated the causal model for effective measurement of urban competitiveness based on the fuzzy DEMATEL method. Begg [23] focused on the factors affecting urban competitiveness and evaluated urban competitiveness from the relationship between input and output. Kresl explores the role of economy in the development of urban competitiveness by studying the relationship between urban competitiveness and urban economy (Kresl and Singh [24]). Gardiner [25] et al. used empirical analysis methods on European cities to explore the relationship between urban competitiveness and economic growth. Esmaeilpoorarabi [26] et al. reviewed domestic and foreign literature such as the symbiotic relationship between quality of life and urban competitiveness and studied the role of soft measures to support urban competitiveness. Matos [27] et al. choose how to improve the competitiveness and sustainability of cities based on urban structural capital. O'Neill [28] et al. analyzed the growth of financial and business services in Australia's economic development to study the relationship between financial services and urban competitiveness.

The development of Huaihe River ecological economic belt plays an important role in promoting the high-quality development of China's economy, so it is particularly important to measure and evaluate the high-quality development of Huaihe River economic belt effectively. At present, only a small part of the foreign literature studies the Huaihe economic belt. Song and Xie [29] et al. used dynamic factor analysis to analyze the panel data of the Huaihe economic belt cities and concluded that the city's economic development stimulated competitiveness and the spatial distribution was not balanced characteristics. Domestic literature has conducted supplementary research on it. Mao [30] et al. empirically investigated the modernization process of industrial coordinated development of Huaihe economic belt with the theory of industrial coordinated development and put forward suggestions on coordination development of liaison mechanism on the basis of analyzing the low level of regional development. Ma and Peng [31] et al. measured the ecological economic development of urban agglomerations in Huaihe River economic belt. Based on the analysis of the unbalanced development of the real economy in each province, the paper proposed that we should strengthen reform and innovation, accelerate the transformation of economic development mode, and promote the coordinated development mechanism of economy and ecological civilization. Ren and Liu [32] et al. believed that the high-quality development of Huaihe River economic belt requires the development and utilization of water resources. Taking regional agriculture as the research object, they calculated and analyzed the temporal and spatial differences of agricultural green water resources utilization rate and efficiency in different cities, studied the impact mechanism, and provided decision support for the coordinated development of water resources in Huaihe River economic belt. Zhou [33] et al. believed that improving efficiency of green economy is the key to the green development of the Yangtze River economic belt and analyzed the influencing factors from the spatial and temporal dimensions. Ren [34] et al. evaluated the ecological efficiency of the Huaihe River economic belt by using the three-stage DEA model and, based on this, put forward some policy recommendations to narrow the regional ecological efficiency difference development from the aspects of industrial transformation, regional coordinated development, and culture and education. Sun and Yi [35] et al. put forward suggestions on the transformation of regional development momentum and the transformation of regional development structure in 
order to achieve high-quality development when the overall economic strength of the Huaihe River Ecological Economic Zone is weak.

The above research enriches the theory and method of high-quality development of Huaihe River economic belt and effectively promotes the high-quality development of Huaihe River economic belt. However, there is no literature to establish a systematic measurement and evaluation system for the high-quality development of Huaihe River economic belt, so as to measure and evaluate the high-quality development of Huaihe River economic belt and quantitatively understand the development situation of Huaihe River economic belt. Therefore, it is necessary to establish a systematic evaluation system for the high-quality development of the Huaihe River economic belt and accurately evaluate the high-quality development of Huaihe River economic belt, which has important practical and theoretical significance.

\section{Connotation and Index System Construction of High-Quality Development in Huaihe River Economic Belt}

3.1. Connotation of High-Quality Development. On the basis of grasping the connotation of high-quality development, this paper scientifically constructs a high-quality development evaluation index system from the perspective of statistical measurement, which mainly reflects the following aspects.

3.1.1. High-Quality Development Is a Dynamic and Sustainable Development of National Economy. In order to achieve high-quality development, GDP, which represents the output level, maintains stable growth, while its internal composition is constantly optimized and its gold content is constantly improved, and the proportion of "two ends" in the global industrial value chain reaches a high level; coordinated development of various proportional relationships means that the three major industries have a good structure, the proportion of investment, export, and consumption is reasonable, and the new economy and new kinetic energy industry have competitive advantages.

\subsubsection{High-Quality Development Is an Efficient Development} Based on Innovation. To achieve high-quality development, it is necessary to achieve a greater output with less input and create greater wealth with less resources. Scientific and technological innovation is the driving force to promote high-quality development. Through scientific and technological innovation, we can optimize the industrial structure, improve the efficiency of input-output, enlarge the role of various factors of productivity, and greatly improve the overall benefit and efficiency of economic development.

3.1.3. High-Quality Development Is a Sustainable Development Driven by Ecological Environment. In order to achieve high-quality development, ecological environment protection should be regarded as one of the core objectives of high-quality development. Ecological environment is an important yardstick to measure the effectiveness of high-quality development. The effect of high-quality development is inseparable from the ecological environment in many aspects. Ecological environment protection is an effective means to promote highquality development. Various practical cases show that if the economic development attaches importance to the development of ecological environment at the beginning, it will be greatly improved and promoted in structure, efficiency, and benefit.

\subsubsection{High-Quality Development Aims at Satisfying People's} Yearning for a Better Life. In order to achieve high-quality development, we should take the realization of the common prosperity of all people as the ultimate goal. The ruling concept of the Communist Party of China is to serve the people wholeheartedly. At present, the main contradiction in China is between the people's growing needs for a better life and the unbalanced and inadequate development. In addition, there are some livelihood problems in our society, such as unbalanced urban and rural development, income distribution problems, and difficult access to a doctor. High-quality development should be reflected in the action guide to provide people's living quality and meet their growing needs for a better life.

3.2. Construction of High-Quality Development Index System of Huaihe River Eco-Economic Belt. To evaluate the highquality development of Huaihe River economic belt, we should not only understand the basic connotation of high-quality development but also consider the characteristics and requirements of Huaihe River ecological economic belt itself. The state requires that the Huaihe River ecological economic belt should be built for the purpose of green development, improve the ecological environment of Huaihe River Ecological basin, promote regional coordinated development, promote economic development quality change, efficiency change, dynamic change, improve people's livelihood, and build a beautiful, livable, harmonious and orderly ecological economic belt. Therefore, this paper constructs a high-quality development evaluation system of the Yangtze River economic belt, which consists of 28 indicators in five aspects: green development, economic quality, innovation ability, people's life, and open cooperation. The index system is shown in Table 1.

Economic vitality index: the evaluation of the quality of economic development should not only consider the indicators that can reflect the level of economic development, such as GDP and per capita GDP, but also consider the indicators that can reflect the quality of economic operation, the degree of regional economic activity and the ability to open to the outside world, the proportion of fiscal revenue to GDP, the dependence on foreign trade, and the proportion of actual utilization of foreign capital are selected.

Innovation efficiency index: innovation is the first driving force of development, and the level of innovation is 
TABLE 1: Evaluation index system of urban competitiveness in Huaihe River eco-economic belt.

\begin{tabular}{|c|c|c|c|}
\hline $\begin{array}{l}\text { Evaluation } \\
\text { perspective }\end{array}$ & Primary indicators & Secondary indicators & Index interpretation \\
\hline \multirow{5}{*}{$\begin{array}{l}\text { Economic } \\
\text { vitality }\end{array}$} & \multirow{4}{*}{ Economic base } & GDP $(+)$ & Gross domestic product \\
\hline & & GDP per capita $(+)$ & GDP/resident population \\
\hline & & Proportion of fiscal revenue in GDP & Fiscal revenue/GDP \\
\hline & & Foreign trade dependence $(\mathrm{o})$ & Total import and export/GDP \\
\hline & Opening up & $\begin{array}{c}\text { Proportion of foreign capital actually } \\
\text { utilized }(+)\end{array}$ & Actual utilization of foreign capital/GDP \\
\hline \multirow{3}{*}{$\begin{array}{l}\text { Innovation } \\
\text { efficiency }\end{array}$} & \multirow{2}{*}{$\begin{array}{l}\text { Technological } \\
\text { innovation }\end{array}$} & $\begin{array}{c}\text { Proportion of science and technology } \\
\text { expenditure }(+)\end{array}$ & Science and technology expenditure/GDP \\
\hline & & Number of patent applications (+) & Number of patent applications/resident population \\
\hline & \multirow[t]{2}{*}{ Industrial optimization } & Advanced index of industrial structure & $\begin{array}{l}\text { Output value of tertiary industry/output value of } \\
\text { secondary industry }\end{array}$ \\
\hline \multirow{6}{*}{$\begin{array}{l}\text { Green } \\
\text { development }\end{array}$} & & $\begin{array}{c}\text { Centralized treatment rate of sewage } \\
\text { treatment plant }(+)\end{array}$ & Quantity of treated sewage/total quantity of sewage \\
\hline & \multirow{4}{*}{$\begin{array}{l}\text { Environmental } \\
\text { protection }\end{array}$} & $\begin{array}{c}\text { Comprehensive utilization of industrial } \\
\text { solid waste }(+)\end{array}$ & $\begin{array}{c}\text { Disposal utilization/production (industrial solid } \\
\text { waste) }\end{array}$ \\
\hline & & Green coverage rate $(+)$ & $\begin{array}{c}\text { Green area of built-up area/total land area of } \\
\text { built-up area }\end{array}$ \\
\hline & & Social instability index $(-)$ & Unemployment rate + CPI \\
\hline & & $\begin{array}{c}\text { Disposable income ratio of urban and } \\
\text { rural residents (o) }\end{array}$ & $\begin{array}{c}\text { Urban/rural residents (per capita disposable } \\
\text { income) }\end{array}$ \\
\hline & \multirow{2}{*}{$\begin{array}{l}\text { Improvement of } \\
\text { people's livelihood }\end{array}$} & Urbanization rate $(+)$ & Urban population/resident population \\
\hline \multirow{4}{*}{ People's life } & & Registered urban unemployment rate & $\begin{array}{l}\text { Urban registered unemployed persons/(urban } \\
\text { employees + urban registered unemployed persons) }\end{array}$ \\
\hline & \multirow{3}{*}{ Education and health } & $\begin{array}{l}\text { Proportion of cultural, educational, } \\
\text { medical, and health expenditure }(+)\end{array}$ & $\begin{array}{c}\text { Education, culture, health, and medical } \\
\text { expenditure/GDP }\end{array}$ \\
\hline & & Health technician/1000 population $(+)$ & Number of health technicians/total population \\
\hline & & $\begin{array}{l}\text { Number of beds in health institutions/ } \\
1000 \text { population }(+)\end{array}$ & $\begin{array}{l}\text { Number of beds in health institutions/total } \\
\text { population }\end{array}$ \\
\hline
\end{tabular}

Note: the "+" in brackets indicates positive index, "-" indicates inverse index, and "O" indicates moderate index.

closely related to the input and output of a region. For specific performance in scientific and technological innovation, as well as the use of scientific and technological innovation to achieve industrial optimization and efficiency improvement, we select the proportion of scientific and technological expenditure, the number of patent applications per 10000 people, and the index of industrial structure upgrading.

Green development index: "green development" is the goal of high-quality development of Huaihe River economic belt. Therefore, centralized treatment rate of sewage treatment plant, comprehensive utilization of industrial solid waste, and green coverage rate of built-up area are selected to reflect green development.

People's living index: people's livelihood is a hot issue in China's society. The sharing of development achievements by the people is the basic requirement of the scientific outlook on development. It is also the basic way for the Chinese nation to achieve common prosperity. Therefore, social instability index, disposable income ratio of urban and rural residents, urbanization rate, urban registered unemployment rate, proportion of cultural, educational, and health expenditure, health technical personnel/1000 population, and number of beds in health institutions/1000 population were selected. Among them, social instability index, disposable income ratio of urban and rural residents, and registered unemployment rate are inverse indicators.

\section{Empirical Study on High-Quality Development of Huaihe Economic Belt}

In this paper, closely combined with the development plan of Huaihe ecological economic belt, according to the new development concept and high-quality development requirements, as well as the "five in one" overall layout, and drawing on the high-quality development evaluation index system constructed by Li [36] et al., this paper selects 25 cities under the jurisdiction of Huaihe ecological economic belt as the basic research unit. The data from 2005 to 2018 are collected. All the data are from China Urban Statistical Yearbook, as well as the calendar yearbook of various provinces and cities, statistical yearbook, and statistical bulletin of each city. Some index values are sorted out and calculated based on the data in the statistical yearbook. From the four evaluation perspectives of economic vitality, innovation efficiency, green development, and people's life, this paper measures the high-quality development of cities in Huaihe ecological economic belt.

\subsection{Selection of Evaluation Methods}

4.1.1. Data Processing. Set $x_{i j}^{t}$ as the value of the city's index in the year, $m_{i j}^{t}$ and $M_{i j}^{t}$ are the minimum value and maximum value of the index in the year, and we use the following formula to standardize the data: 


$$
x_{i j}^{\prime}=\left\{\begin{array}{l}
\frac{\left(x_{i j}^{t}-m_{i j}^{t}\right)}{\left(M_{i j}^{t}-m_{i j}^{t}\right)}, \\
\frac{\left(M_{i j}^{t}-x_{i j}^{t}\right)}{\left(M_{i j}^{t}-m_{i j}^{t}\right)} .
\end{array}\right.
$$

As for the two moderate indicators used in this paper (foreign trade dependence and the ratio of urban and rural residents' disposable income), the proportion of foreign trade dependence in the Huaihe ecological economic group is relatively low, and it still exists as a good indicator. Therefore, in data processing, positive indicators are used, while social instability index, disposable income of urban and rural residents, and urban registered unemployment rate are inversely indicated standardized treatment.

\subsubsection{Comprehensive Evaluation and Calculation of Urban} High-Quality Development. Use the entropy weighting method to determine the weight of each indicator, and calculate the comprehensive evaluation value of the city's competitiveness. The specific steps are as follows.

The proportion of the $i$ sample index value under the $j$ index is calculated as

$$
p_{i j}=\frac{x_{i j}^{\prime}}{\sum_{i=1}^{m} x_{i j}^{\prime}}, \quad\left(0 \leq p_{i j} \leq 1\right) .
$$

The information entropy value of the $j$ indicator is calculated as

$$
\begin{aligned}
e_{j} & =-k \sum_{i=1}^{m} p_{i j} \ln p_{i j}, \\
k & =\frac{1}{\ln m} .
\end{aligned}
$$

Information entropy redundancy is calculated as

$$
d_{j}=1-e_{j}
$$

The weight of the $j$ indicator is calculated as

$$
w_{j}=\frac{d_{j}}{\sum_{i=1}^{m} d_{j}} .
$$

The composite score is calculated as

$$
s=\sum_{i=1}^{n} p_{i j} w_{j}
$$

\subsection{Result Analysis}

4.2.1. View in Its Entirety. The final calculation results are shown in Table 2. From 2005 to 2018, except Suqian, several cities in Jiangsu Province with strong economic strength ranked top in terms of urban competitiveness, among which Yangzhou and Taizhou have almost remained the top three in recent years except for 2018 .
However, with the higher score of Xuzhou in the index of foreign trade dependence in 2018, Xuzhou's economic growth will be promoted and its comprehensive score will be improved as a whole. And Huaian City and Yancheng City scored significantly higher than Yangzhou and Taizhou in the number of patent applications per 10000 people, which led to the scientific and technological innovation of Huai'an and Yancheng, increased the research and development of high-tech industries, and made their comprehensive score into the top three. In the comprehensive score data of 2018, Yangzhou's economic vitality score decreased by $21.49 \%$ compared with the same period last year, and the innovation efficiency score decreased by $26.93 \%$ compared with the same period last year; Taizhou's economic vitality score decreased by $66.10 \%$ compared with the same period last year, and the innovation efficiency score decreased by $62.76 \%$ compared with the same period last year. This makes Yangzhou and Taizhou rank among the top three in terms of comprehensive scores in 2018. Yancheng is at a disadvantage in terms of per capita GDP due to its large population. However, due to its large geographical area, the local government has increased the coordinated development of agriculture, industry, and the tertiary industry, which makes its comprehensive ranking in the forefront in recent years. Although Lianyungang is the forefront of coastal opening up, due to the inconvenient land transportation, the competition of surrounding cities, and the overall economic development, trend of Jiangsu Province is driven by the south of Jiangsu Province and then extended to the north of Jiangsu Province. Therefore, the economic radiation that can be obtained is less, and the comprehensive development level is gradually weakened. Xuzhou, which connects Jiangsu, Shandong, Henan, and Anhui Provinces, is also one of the important capital distribution centers, material gathering centers, and transportation hubs of the four provinces. Its comprehensive development level is relatively stable. In recent two years, Xuzhou has attached importance to relying on its convenient transportation advantages, increasing investment in foreign trade import and export, and its overall comprehensive ranking has steadily improved. From the perspective of eco-environmental indicators, Jiangsu Province, which ranks first in China, has a good ecological environment in Huaihe ecological economic belt. Except for Jining, the economic gap between the four prefecture level cities in Shandong Province has gradually widened, the innovation driven efficiency is not obvious, there is lack of growth momentum, and the city competitiveness ranking has declined to varying degrees.

In recent years, most of the cities in Anhui Province, which are unknown in the central part of China, have risen quietly in recent years. The comprehensive score of Bengbu City is in the front seat in recent years, which is in the forefront of the development of prefecture level cities in Anhui Province. Anhui Province has achieved good results by taking Hefei as the center and then radiating the whole province. As the transportation hub of Huaihe River ecological economic belt, Bengbu City will gradually become the 
TABLE 2: Valuation value and ranking of urban competitiveness in Huaihe ecological economic belt.

\begin{tabular}{|c|c|c|c|c|c|c|c|c|c|c|c|c|c|c|}
\hline Year & 2005 & 2006 & 2007 & 2008 & 2009 & 2010 & 2011 & 2012 & 2013 & 2014 & 2015 & 2016 & 2017 & 2018 \\
\hline \multirow{2}{*}{ Huaian } & 0.438 & 0.469 & 0.544 & 0.484 & 0.466 & 0.499 & 0.560 & 0.553 & 0.576 & 0.507 & 0.539 & 0.508 & 0.500 & 0.518 \\
\hline & 9 & 7 & 6 & 6 & 6 & 5 & 4 & 3 & 3 & 5 & 4 & 7 & 7 & 3 \\
\hline \multirow{2}{*}{ Yancheng } & 0.554 & 0.512 & 0.580 & 0.501 & 0.494 & 0.483 & 0.561 & 0.553 & 0.516 & 0.535 & 0.594 & 0.584 & 0.574 & 0.583 \\
\hline & 5 & 6 & 5 & 5 & 4 & 6 & 3 & 4 & 6 & 3 & 3 & 3 & 3 & 1 \\
\hline \multirow{2}{*}{ Suqian } & 0.264 & 0.306 & 0.356 & 0.349 & 0.374 & 0.358 & 0.386 & 0.403 & 0.422 & 0.445 & 0.444 & 0.448 & 0.409 & 0.505 \\
\hline & 20 & 17 & 13 & 10 & 8 & 10 & 10 & 8 & 8 & 8 & 9 & 9 & 10 & 4 \\
\hline \multirow{2}{*}{ Xuzhou } & 0.597 & 0.553 & 0.581 & 0.522 & 0.477 & 0.501 & 0.558 & 0.537 & 0.528 & 0.487 & 0.525 & 0.532 & 0.528 & 0.583 \\
\hline & 2 & 4 & 4 & 4 & 5 & 4 & 5 & 5 & 5 & 6 & 7 & 5 & 5 & 2 \\
\hline \multirow{2}{*}{ Lianyungang } & 0.595 & 0.570 & 0.606 & 0.583 & 0.550 & 0.531 & 0.531 & 0.535 & 0.531 & 0.535 & 0.535 & 0.516 & 0.526 & 0.475 \\
\hline & 3 & 3 & 3 & 3 & 3 & 3 & 6 & 6 & 4 & 4 & 5 & 6 & 6 & 7 \\
\hline \multirow{2}{*}{ Yangzhou } & 0.633 & 0.660 & 0.684 & 0.675 & 0.675 & 0.708 & 0.697 & 0.635 & 0.636 & 0.573 & 0.628 & 0.586 & 0.629 & 0.472 \\
\hline & 1 & 1 & 1 & 1 & 1 & 1 & 1 & 1 & 1 & 1 & 1 & 2 & 1 & 8 \\
\hline \multirow{2}{*}{ Taizhou } & 0.568 & 0.602 & 0.646 & 0.599 & 0.579 & 0.578 & 0.621 & 0.605 & 0.594 & 0.542 & 0.599 & 0.597 & 0.604 & 0.462 \\
\hline & 4 & 2 & 2 & 2 & 2 & 2 & 2 & 2 & 2 & 2 & 2 & 1 & 2 & 9 \\
\hline \multirow{2}{*}{ Zaozhuang } & 0.482 & 0.440 & 0.405 & 0.390 & 0.345 & 0.348 & 0.338 & 0.323 & 0.333 & 0.291 & 0.361 & 0.433 & 0.349 & 0.330 \\
\hline & 7 & 9 & 9 & 9 & 12 & 11 & 12 & 14 & 14 & 15 & 13 & 10 & 16 & 18 \\
\hline \multirow{2}{*}{ Jining } & 0.550 & 0.516 & 0.497 & 0.399 & 0.369 & 0.381 & 0.399 & 0.377 & 0.394 & 0.350 & 0.422 & 0.389 & 0.405 & 0.360 \\
\hline & 6 & 5 & 7 & 7 & 9 & 8 & 8 & 10 & 10 & 10 & 10 & 12 & 11 & 14 \\
\hline \multirow{2}{*}{ Linyi } & 0.467 & 0.445 & 0.435 & 0.393 & 0.389 & 0.394 & 0.387 & 0.393 & 0.406 & 0.343 & 0.382 & 0.385 & 0.342 & 0.327 \\
\hline & 8 & 8 & 8 & 8 & 7 & 7 & 9 & 9 & 9 & 11 & 11 & 13 & 17 & 19 \\
\hline \multirow{2}{*}{ Heze } & 0.379 & 0.342 & 0.371 & 0.312 & 0.284 & 0.261 & 0.290 & 0.291 & 0.293 & 0.285 & 0.318 & 0.298 & 0.316 & 0.289 \\
\hline & 13 & 13 & 11 & 14 & 15 & 16 & 16 & 17 & 17 & 16 & 15 & 20 & 19 & 23 \\
\hline \multirow{2}{*}{ Bengbu } & 0.370 & 0.326 & 0.297 & 0.337 & 0.346 & 0.371 & 0.423 & 0.443 & 0.450 & 0.475 & 0.527 & 0.548 & 0.528 & 0.484 \\
\hline & 14 & 14 & 16 & 12 & 11 & 9 & 7 & 7 & 7 & 7 & 6 & 4 & 4 & 6 \\
\hline \multirow{2}{*}{ Fuyang } & 0.344 & 0.283 & 0.207 & 0.185 & 0.212 & 0.186 & 0.209 & 0.240 & 0.262 & 0.261 & 0.299 & 0.324 & 0.36 & 0.391 \\
\hline & 15 & 19 & 23 & 25 & 23 & 23 & 22 & 21 & 19 & 18 & 17 & 17 & 15 & 13 \\
\hline \multirow{2}{*}{ Luan } & 0.303 & 0.275 & 0.208 & 0.200 & 0.226 & 0.222 & 0.228 & 0.255 & 0.241 & 0.252 & 0.281 & 0.293 & 0.383 & 0.403 \\
\hline & 17 & 20 & 22 & 24 & 21 & 20 & 20 & 19 & 20 & 20 & 20 & 21 & 12 & 12 \\
\hline \multirow{2}{*}{ Bozhou } & 0.194 & 0.181 & 0.164 & 0.217 & 0.226 & 0.210 & 0.247 & 0.245 & 0.236 & 0.247 & 0.261 & 0.320 & 0.314 & 0.342 \\
\hline & 24 & 25 & 25 & 20 & 22 & 21 & 19 & 20 & 21 & 21 & 22 & 18 & 20 & 17 \\
\hline \multirow{2}{*}{ Huaibei } & 0.409 & 0.361 & 0.373 & 0.345 & 0.362 & 0.340 & 0.353 & 0.346 & 0.347 & 0.342 & 0.351 & 0.352 & 0.374 & 0.345 \\
\hline & 10 & 12 & 10 & 11 & 10 & 12 & 11 & 13 & 13 & 12 & 14 & 15 & 13 & 16 \\
\hline \multirow{2}{*}{ Chuzhou } & 0.287 & 0.293 & 0.288 & 0.262 & 0.273 & 0.287 & 0.337 & 0.368 & 0.383 & 0.406 & 0.445 & 0.465 & 0.470 & 0.501 \\
\hline & 18 & 18 & 17 & 17 & 17 & 14 & 14 & 11 & 11 & 9 & 8 & 8 & 8 & 5 \\
\hline \multirow{2}{*}{ Luohe } & 0.396 & 0.386 & 0.345 & 0.257 & 0.264 & 0.273 & 0.284 & 0.294 & 0.353 & 0.327 & 0.377 & 0.399 & 0.411 & 0.416 \\
\hline & 11 & 11 & 14 & 18 & 18 & 15 & 17 & 16 & 12 & 13 & 12 & 11 & 9 & 10 \\
\hline \multirow{2}{*}{ Pingdingshan } & 0.279 & 0.323 & 0.323 & 0.293 & 0.326 & 0.260 & 0.327 & 0.314 & 0.300 & 0.273 & 0.316 & 0.352 & 0.368 & 0.416 \\
\hline & 19 & 15 & 15 & 15 & 13 & 17 & 15 & 15 & 16 & 17 & 16 & 16 & 14 & 11 \\
\hline
\end{tabular}

Note: source: author's calculation. Limited to space, this is not included in the overall ranking of Huainan, Suzhou, Xinyang, Zhumadian, Zhoukou, and Shangqiu.

leader of the economic belt by speeding up the construction of aviation facilities under the condition of such perfect land and water transportation infrastructure. At the same time, the comprehensive score of Chuzhou City in Anhui Province has been steadily improved in recent years, fully showing the development potential of Chuzhou City. In the future, Chuzhou City will rely more on the radiation and driving role of Nanjing City to accelerate its development speed. The comprehensive level of urban competitiveness of several prefecture level cities in Henan Province is relatively low, which is mainly due to the joint effect caused by economic backwardness.

Based on the comprehensive scores of each city from 2005 to 2018, the average value is taken, and the horizontal clustering results are shown in Table 3 . It can be seen that the comprehensive development level of Huaihe River ecological economic belt is generally characterized by "high in the west and low in the east." The lower reaches play a leading role in the high-quality development of the regional economic belt, and the "three levels" and "three flow sections" do not completely overlap.

\subsection{From Different Perspectives}

4.3.1. Economic Vitality Perspective. From the perspective of economic vitality, this paper selects the cities with the highest scores of economic vitality in each province for comparative analysis. As shown in Figure 1, on the whole, the economic vitality scores of Yangzhou and Xuzhou in Jiangsu Province are higher than those of other provinces. The economic vitality score of Bengbu City in Anhui Province is similar to that of Jining City in Shandong Province, and the economic vitality score of Luohe City in Henan Province is relatively low. Among them, Xuzhou's economic vitality score trend shows a "W" trend, which is 0.18 points in 2011 as the inflection point; 
TABLE 3: Clustering of average score level based on comprehensive evaluation.

\begin{tabular}{lccc}
\hline & $\begin{array}{c}\text { The first level (average score } \\
\geq 0.52)\end{array}$ & $\begin{array}{c}\text { The second level }(0.35 \leq \text { average } \\
\text { score }<0.52)\end{array}$ & The third level $(0 \leq$ average score $<0.35)$ \\
\hline $\begin{array}{l}\text { Prefecture } \\
\text { level city }\end{array}$ & $\begin{array}{c}\text { Yangzhou, Taizhou, } \\
\text { Yancheng, Xuzhou, } \\
\text { Lianyungang }\end{array}$ & $\begin{array}{c}\text { Huaian, Suqian, Jining, } \\
\text { Zaozhuang, Linyi, Bengbu, }\end{array}$ & $\begin{array}{c}\text { Heze, Fuyang, Luan, Bozhou, Huaibei, Suzhou, } \\
\text { Huainan, Luohe, Pingdingshan, Shangqiu, Zhoukou, } \\
\text { Xinyang, Zhumadian }\end{array}$ \\
Location & $\begin{array}{c}\text { All of them are located in the } \\
\text { lower reaches of Huaihe River }\end{array}$ & $\begin{array}{c}\text { Most of them are located in the } \\
\text { middle reaches of Huaihe River }\end{array}$ & $\begin{array}{c}\text { Some of them are located in the upper reaches of } \\
\text { Huaihe River }\end{array}$ \\
\hline
\end{tabular}

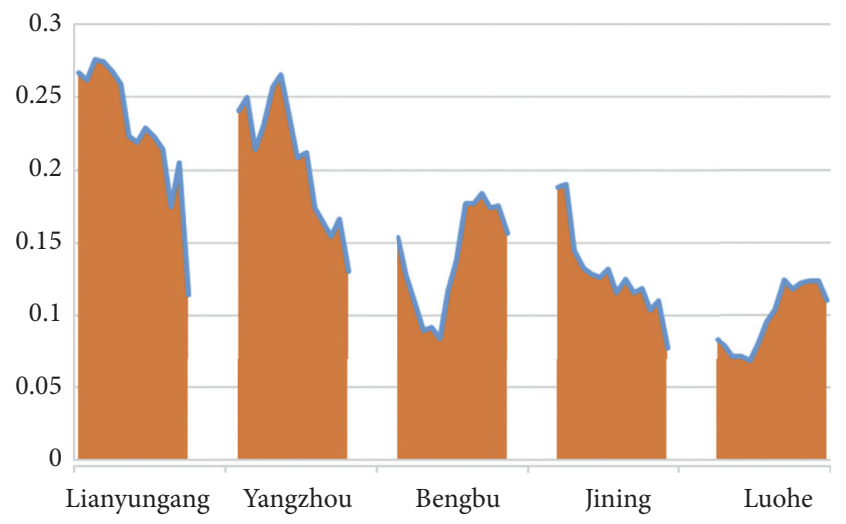

FIGURE 1: Comparison of economic vitality and competitiveness of some cities over the years.

Yangzhou City, as the top city in comprehensive urban competitiveness, and its economic vitality shows a downward trend, but compared with other provinces, it is still at a higher level. Moreover, compared with other four cities in 2015-2013, Yangzhou's economic vitality score exceeded 0.20 , while the other four cities scored within 0.2 between 2005 and 2018; Bengbu City continued to decline to the lowest score of 0.08 before 2010, and since then, the economic vitality has been steadily improved in recent years, among which Bengbu City ranked the top in economic vitality in 2015, 2016, and 2017. First, its vigorous development trend helps to drive the effective operation of Huaihe ecological economic belt; Jining City's economic vitality score showed a continuous downward trend and fell to the lowest value of 0.078 points in 2018 , which was also the lowest value of other four cities, and its economic development situation was not optimistic; Luohe City's overall score of economic vitality was low, but the trend of economic vitality score showed an upward trend. The rapid economic development in the later period laid a good foundation.

Secondly, we choose 2005, 2017, and 2018 to compare the economic vitality of cities in Huaihe ecological economic belt. As shown in Figure 2, Lianyungang City, Yangzhou City, and Jining City have great changes in economic vitality and competitiveness. Among them, Yangzhou City, as the "first city of China's canal," has gradually weakened its economic vitality due to the impact of financial crisis and debt sovereign crisis of European and American countries. Bengbu City has steadily improved in terms of economic vitality and ranked the top three in 2017 and 2018. This is mainly due to its own geographical and environmental advantages, good policy environment, and economic radiation from the central and western regions, so it has great development space and potential.
4.3.2. Innovation Perspective. From the perspective of innovation efficiency, this paper selects the cities with the highest innovation efficiency scores in each province for comparative analysis. As shown in Figure 3, on the whole, the innovation efficiency scores of Yangzhou and Taizhou in Jiangsu Province are higher than those of other provinces, Bengbu City of Anhui Province is lower than Yangzhou and Taizhou City, which is in the middle, and Jining City of Shandong Province and Pingdingshan City of Henan Province are on the low side. Among them, Yangzhou and Taizhou, as the top cities in comprehensive urban competitiveness, have been maintaining a greater advantage although they have fluctuated in recent years. However, in 2018, the score of innovation efficiency dropped by a cliff, which was closely related to the decrease in science and technology expenditure. Although the score of innovation efficiency in Bengbu City decreased in some years, it showed an overall upward trend, which may be the driving role of its own economic vitality. Jining City's innovation efficiency score showed a continuous downward trend and fell to the lowest value of 0.038 in 2013 . The overall score of innovation efficiency in Pingdingshan City is low, which also fell to the lowest value of 0.017 in 2013, and then the score showed a gradual upward trend. It can be seen that Jining City and Pingdingshan City have achieved great results after innovation efficiency reforms after 2013.

Secondly, we choose 2005, 2017, and 2018 to compare the innovation efficiency of cities in Huaihe ecological economic belt. As shown in Figure 4, compared with 2005, Bengbu City and Suqian City have greater positive changes in innovation efficiency competitiveness. With the gradual improvement of economic vitality, Bengbu City has gradually increased its expenditure on science and technology, thus gradually increasing the number of patents of scientific achievements, and the innovation efficiency has been significantly improved. Compared with 2017, Suqian City's competitiveness has greatly improved other cities, and the reason is that the municipal government in 2018 increased the importance of scientific and technological innovation and steadily improved in science and technology and industrial structure, making Suqian City in the forefront of comprehensive scores in 2018. Among them, Yancheng City, Huai'an City, and Lu'an City have high innovation efficiency, which makes these cities in the forefront of comprehensive scores of each city in 2018. Affected by the economic slowdown, the competitiveness of innovation efficiency of Lianyungang City, Shandong Province, and Henan Province shows a large reverse 


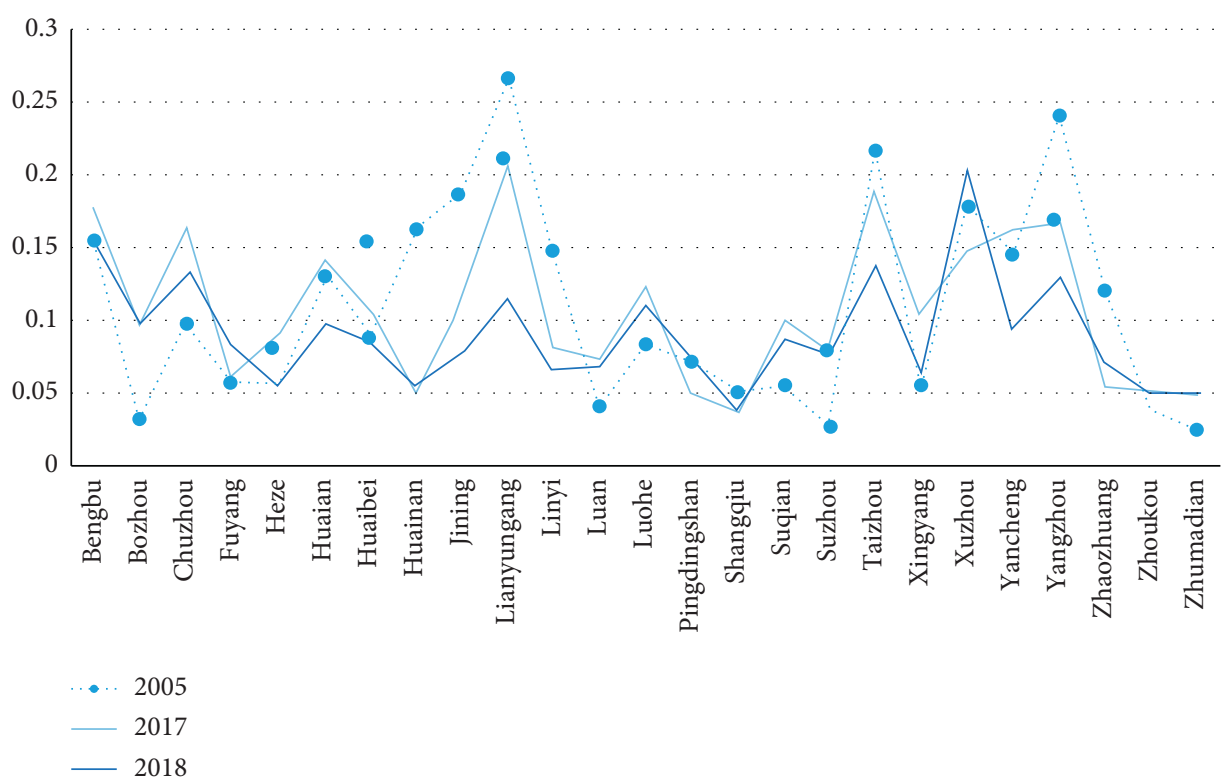

FIGURE 2: Comparison of innovation efficiency competitiveness of some cities over the years.

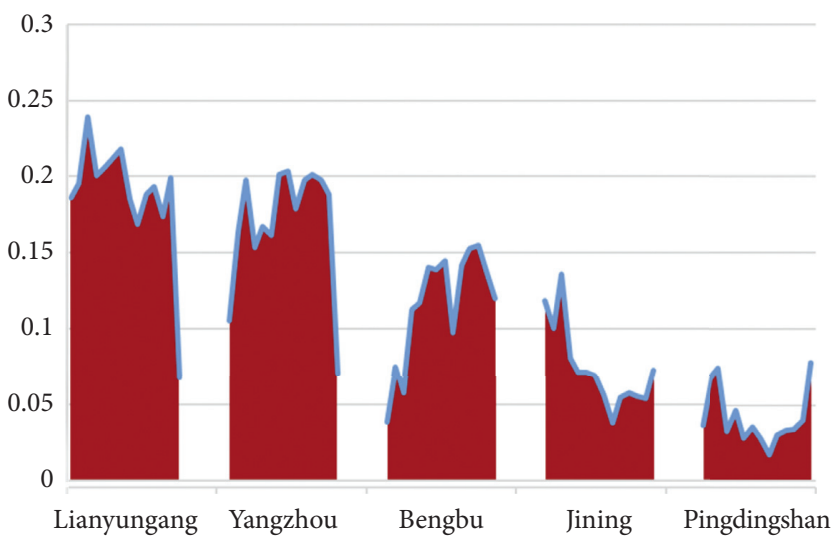

FIgURE 3: Comparison of economic vitality and competitiveness among cities.

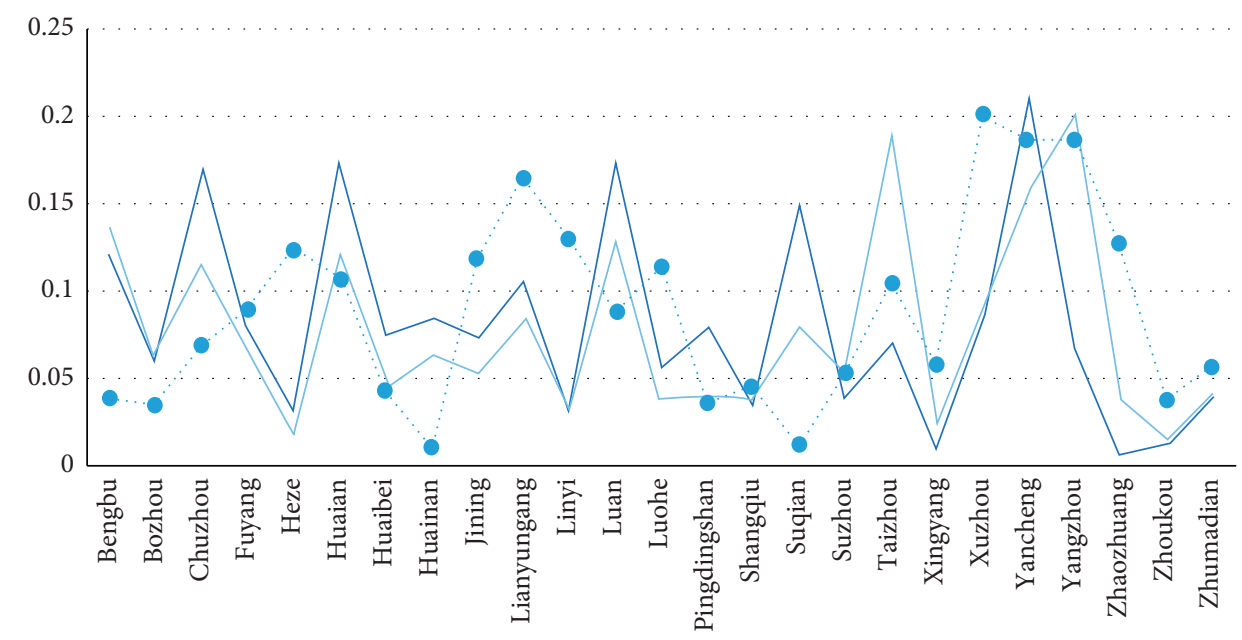

2005
$-\quad 2017$
$-\quad 2018$

FIGURE 4: Comparison of innovation efficiency competitiveness among cities. 
change, and its input and output of science and technology have decreased.

4.3.3. Green Development Perspective. As the ecological development of cities in Huaihe River eco-economic belt is relatively balanced, this paper only selects 2005,2017 , and 2018 for comparison. According to the requirements of development plan, green development is the first important meaning of Huaihe River ecological economic belt planning. As shown in Figure 5, compared with 2005, Taizhou and Yangzhou, the top three in terms of comprehensive competitiveness, have shown a downward trend in terms of green development competitiveness due to the weakening of their treatment capacity for sewage and industrial solid waste; on the contrary, the cities with steadily improved comprehensive competitiveness, such as Bengbu and Chuzhou, have significantly improved their green development.

4.3.4. People's Life Perspective. From the perspective of people's life, this paper still selects 2005, 2017, and 2018 for comparative analysis. As shown in Figure 6, the gradual development of land and sea transportation hubs in Xuzhou and Lianyungang and the better control of social instability index in recent years by several cities with high comprehensive scores, such as Yangzhou and Yan'an, have significantly improved the competitiveness of people's lives. On the contrary, in Huaibei, Huainan, Jining, and other cities, with the stagnation of traffic development and the lower level of education, culture, and medical expenditure, people's living competitiveness is relatively low, while in Taizhou City, with the gap between urban and rural residents' disposable income gradually widened and the proportion of cultural, educational, medical, and health expenditure at a lower level, people's living competitiveness has not changed significantly compared with 2005 to change.

\section{Spatial Correlation Analysis of Urban Competitiveness}

5.1. Global Correlation Analysis. This paper analyzes the time dimension of the evaluation index of the high-quality development of the Huaihe River economic belt. Next, the overall Moran's I spatial autocorrelation analysis is conducted on the urban competitiveness score data of 25 counties and cities in the Huaihe River ecological economic belt from 2005 to 2018 . The global Moran index is defined as follows:

$$
I=\frac{\sum_{i=1}^{n} \sum_{j=1}^{n} w_{i j}\left(X_{i}-\bar{X}\right)\left(X_{j}-\bar{X}\right)}{s^{2} \sum_{i=1}^{n} \sum_{j=1}^{n} w_{i j}},
$$

where $x_{i j}$ denotes comprehensive evaluation value of competitiveness of each city and $w_{i j}$ means normalized spatial weight matrix.

It can be seen from Figure 7 that Moran's I index values of Huaihe River eco-economic belt from 2005 to 2018 are all $>0$, and all of them have passed the test at the significance level of $1 \%$, indicating that there is spatial positive correlation in Huaihe ecological economic belt, and it has the characteristics of spatial agglomeration. Overall, from 2005 to 2018, Moran's I value of Huaihe eco-economic belt increased from 0.396 in 2005 to 0.609 in 2016, indicating that the spatial agglomeration of Huaihe eco-economic belt is increasing. Moreover, Moran's I index changed significantly, with the highest value of 0.665 in 2014, which experienced an obvious upward trend. In the rising section, it shows that, since 2005, with the Huaihe River ecological economic belt relying on the location conditions and national policies, the development speed of comprehensive competitiveness of counties and cities has been accelerating, and the efficiency has also been improving; however, after 2016, Moran's value has declined, falling to 0.426 in 2018. In the decline section, it shows that, after 2016, the influence of neighborhood effect on the development of comprehensive competitiveness of cities in Huaihe River region has gradually weakened, and the development of interregional industrial structure is unreasonable.

5.2. Local Correlation Analysis. The local spatial correlation statistic index is a measure of whether there is spatial autocorrelation at each position in the sample and is used to capture the presence or absence of significant spatial agglomeration or outliers in each spatial region. It can be divided according to the characteristics of each region in four situations: significant local agglomeration (including $\mathrm{HH}$ or LL) or local spatial abnormalities (including HL or LH). The local Moran's I statistic can be given as

$$
I_{i}=\frac{\left(x_{i}-\bar{x}\right)}{S^{2}} \sum_{j=1}^{n} w_{i j}\left(x_{j}-\bar{x}\right)^{2} .
$$

In order to further and intuitively explore the local correlation between the comprehensive competitiveness of 25 counties and cities in Huaihe eco-economic belt from 2005 to 2018, this paper analyzes the local correlation of the comprehensive competitiveness scores in 2005, 2010, 2015, and 2018, as shown in Table 4.

By comparing the results of local autocorrelation in four years, we can see that most cities in Huaihe River eco-economic belt are located in the first and third quadrants, showing positive spatial connection, and the agglomeration types of local autocorrelation are high high and low low, and $\mathrm{HH}$ area is mainly concentrated in the lower reaches of Huaihe River, which indicates that Yangzhou, Taizhou, and other prefecture level cities with high economic development tend to be adjacent. In addition, in terms of quantity, the number of $\mathrm{HH}$ regions decreased from 9 in 2005 to 7 in 2018, indicating that the radiation driving effect of $\mathrm{HH}$ region to adjacent regions is weakening. The LL region is mainly concentrated in the middle and upper reaches of the Huaihe River, which indicates that the undeveloped prefecture level cities in the middle and upper reaches of the Huaihe River tend to be surrounded by some prefecture level cities with low economic development level, which has little change 


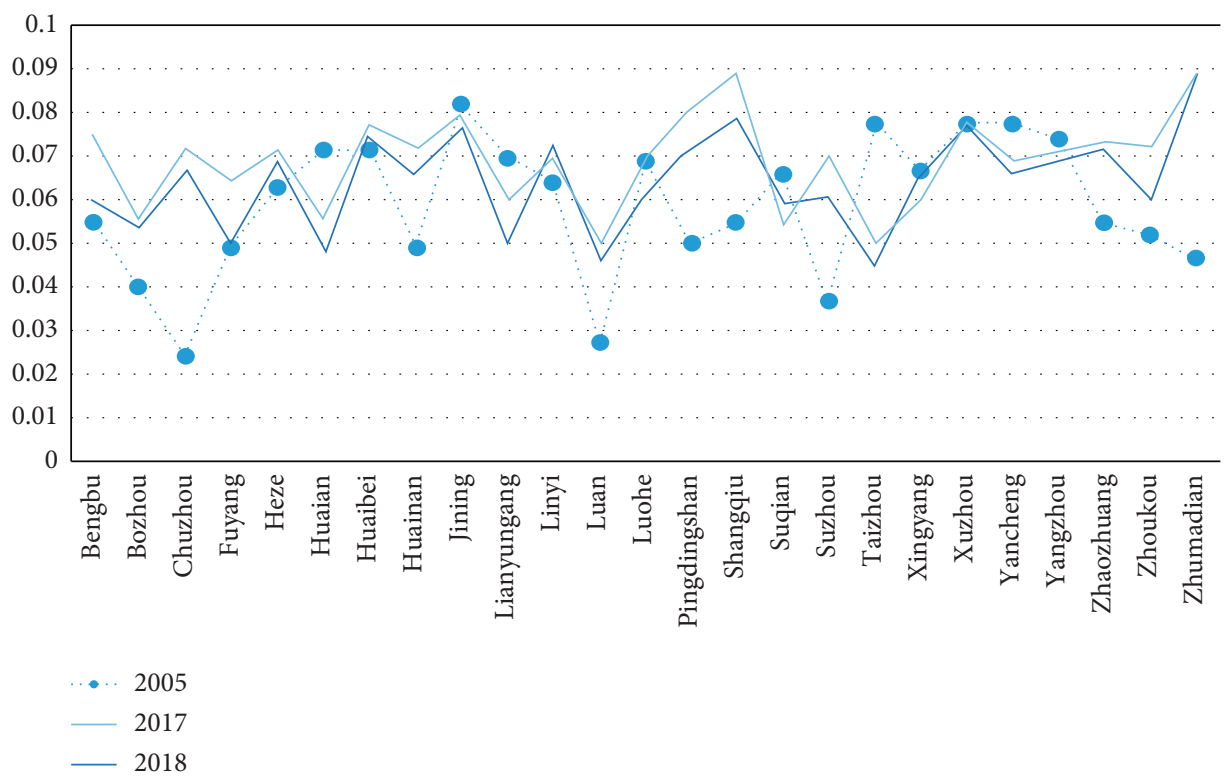

FIgURE 5: Comparison of green development competitiveness among cities.

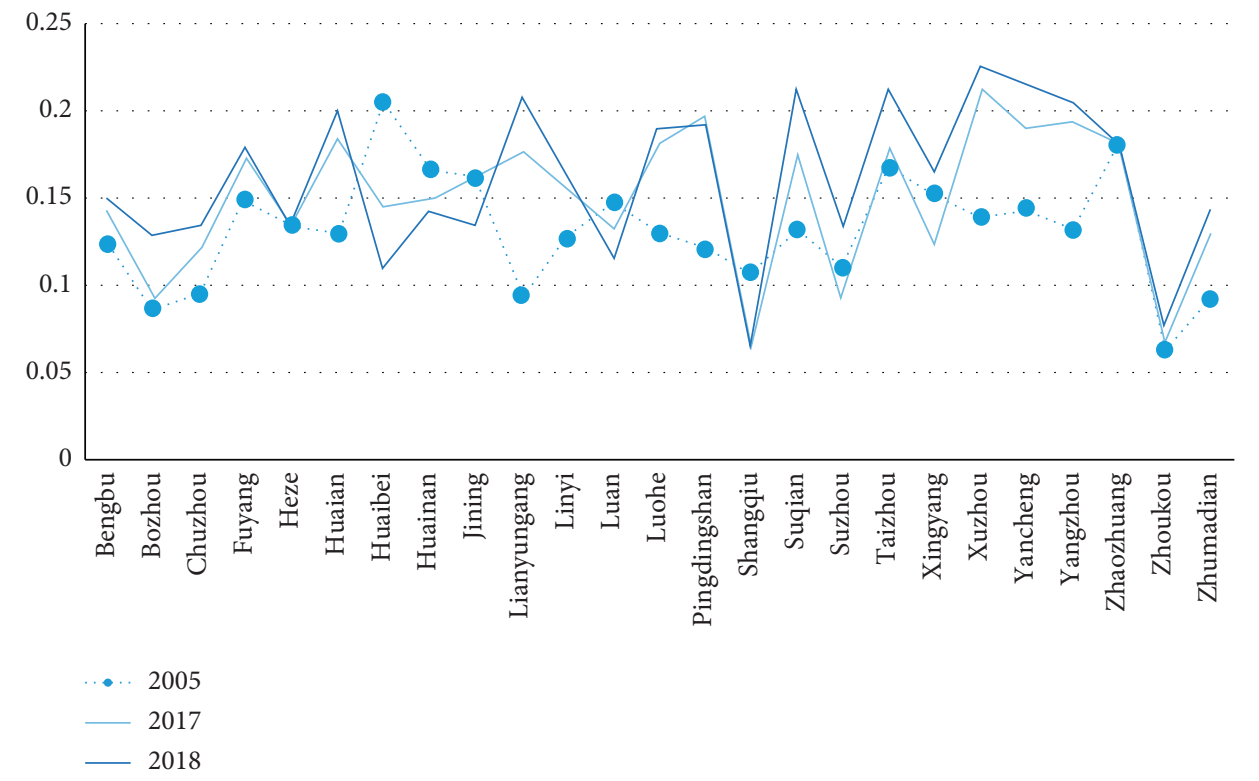

FIGURE 6: Comparison of people's living competitiveness in different cities.

before 2010 and gradually decreases after 2010, which indicates that the coordinated development among regions of Huaihe River ecological economic belt has been gradually improved. The LH region remained basically unchanged, but some cities changed. Suqian City changed from the $\mathrm{LH}$ area to $\mathrm{HH}$ area after 2010, which shows that the spatial difference between the middle and lower reaches of Huaihe River is shrinking, and the spatial connection is gradually strengthened. Chuzhou is transformed from the LH region to $\mathrm{HH}$ region after 2015, which indicates that Chuzhou is affected by the counties and cities in Jiangsu Province with rapid economic development in the lower reaches of Huaihe River and adjacent to Nanjing. The number of HL regions remained at 1 from 2000 to 2015 and increased to 3 in 2018. Luohe City and Pingdingshan City transformed from the LL area to HL region, which shows that Luohe and Pingdingshan have paid attention to the comprehensive development of cities in recent years, and then, their comprehensive competitiveness has been improved, but the performance of their surrounding areas has not been significant to limit its development. Bengbu City has been living in the HL area since 2010, and its surrounding areas have been showing no significant difference, which shows that 


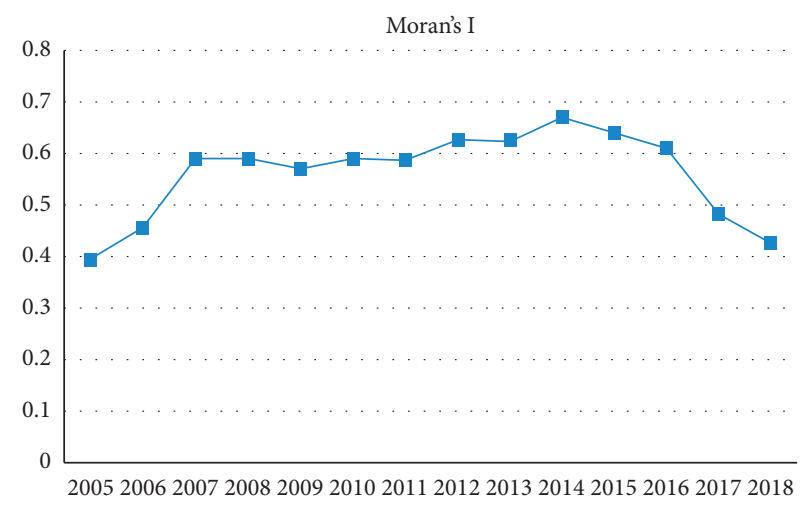

(a)

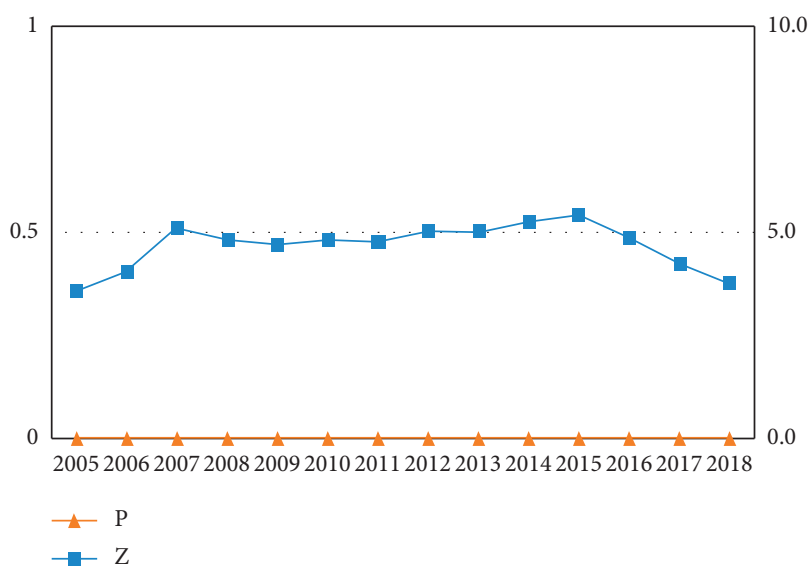

(b)

Figure 7: Analysis on the overall correlation of comprehensive competitiveness of cities.

TABLE 4: Changes in Moran scatter diagram of competitiveness of Huaihe eco-economic city.

\begin{tabular}{|c|c|c|c|c|}
\hline Quadrant & $\mathrm{HH}$ & $\mathrm{LH}$ & LL & HL \\
\hline 2005 & $\begin{array}{c}\text { Huaian, Yancheng, Xuzhou, } \\
\text { Lianyungang, Yangzhou, Taizhou, } \\
\text { Zaozhuang, Jining, Linyi }\end{array}$ & $\begin{array}{l}\text { Suqian, Heze, } \\
\text { Chuzhou }\end{array}$ & $\begin{array}{c}\text { Bengbu, Fuyang, Luan, Bozhou, Xingyang, } \\
\text { Zhumadian, Zhoukou, Shangqiu, } \\
\text { Pingdingshan }\end{array}$ & Huaibei \\
\hline 2010 & $\begin{array}{l}\text { Huaian, Yancheng, Suzhou, Xuzhou, } \\
\text { Lianyungang, Yangzhou, Taizhou, Jining, } \\
\text { Linyi }\end{array}$ & $\begin{array}{l}\text { Heze, Chuzhou, } \\
\text { Suzhou }\end{array}$ & $\begin{array}{c}\text { Fuyang, Luan, Bozhou, Xinyang, } \\
\text { Zhumadian, Zhoukou, Luohe, Shangqiu, } \\
\text { Pingdingshan }\end{array}$ & Bengbu \\
\hline 2015 & $\begin{array}{c}\text { Huaian, Yancheng, Suqian, Xuzhou, } \\
\text { Lianyungang, Yangzhou, Taizhou, } \\
\text { Chuzhou }\end{array}$ & $\begin{array}{l}\text { Zaozhuang, Suzhou, } \\
\text { Huaibei }\end{array}$ & $\begin{array}{c}\text { Huainan, Fuyang, Luanshi, Bozhoushi, } \\
\text { Zhumadian, Zhoukou, Shangqiu, } \\
\text { Pingdingshan }\end{array}$ & Bengbu \\
\hline 2018 & $\begin{array}{l}\text { Huaian, Yancheng, Suqian, Lianyungang, } \\
\text { Yangzhou, Taizhou, Chuzhou }\end{array}$ & $\begin{array}{l}\text { Zaozhuang, Huainan, } \\
\text { Suzhou, Huaibei }\end{array}$ & $\begin{array}{l}\text { Jining, Linyi, Heze, Bozhou, Xingyang, } \\
\text { Zhumadian, Zhoukou, Shangqiu }\end{array}$ & $\begin{array}{l}\text { Bengbu, } \\
\text { Luohe, } \\
\text { Pingdingshan }\end{array}$ \\
\hline
\end{tabular}

Bengbu City has a big difference with the surrounding areas, and the construction and development of Bengbu City as the center city needs to be further improved.

\section{Spatial Convergence Analysis of Urban Competitiveness}

On the basis of clarifying the spatial differences of urban competitiveness level in Huaihe economic belt, it is necessary to further test the development trend of urban competitiveness level in the future, whether it is convergence or divergence, so as to promote the overall improvement of urban competitiveness level in the economic belt.

6.1. $\alpha$-Convergence Test. $\alpha$-convergence means that the gap of per capita income in different countries or regions tends to decrease with the passage of time, which can directly show the change in the distribution pattern of the overall income in the region. If there is $\alpha_{t+1}<\alpha_{t}$ for any $\mathrm{t}$, there will be $\alpha$-convergence, which means that the income gap of the economy is getting smaller and smaller. Similarly, the $\alpha$-convergence method can also analyze the convergence of urban competitiveness. The calculation equation is as follows:

$$
\alpha=\sqrt{\frac{1}{n} \sum \frac{\left(y_{j}-\bar{y}\right)^{2}}{y}},
$$

where $\alpha$ is the coefficient of variation, $y_{j}$ is the level of urban competitiveness, and $\bar{y}$ is the average value of the level of urban competitiveness.

The coefficient of variation is generally used to measure the convergence. In order to explore the convergence of the current level of urban competitiveness in the Huaihe economic belt, this paper calculates the $\alpha$ value of urban competitiveness in the Huaihe area from 2005 to 2018, and the results are shown in Table 5 .

On the whole, the $\alpha$-value of urban competitiveness of Huaihe economic belt shows a downward trend, which indicates that the regional differences of the economic belt are narrowing, showing the $\alpha$-convergence of local years. Among them, Jiangsu Province presents $\alpha$-convergence, Shandong Province, Anhui Province, and Henan Province $\alpha$ value fluctuates up and down, and the $\alpha$-convergence is not obvious. The main reason is that since the Huaihe River economic belt was put forward, it has promoted the overall stable development of cities in the Huaihe River area. However, in the case of the coordinated development of 
TABle 5: The $\alpha$-value of the urban competitiveness of the Huaihe eco-economic belt.

\begin{tabular}{lcccccccccccccc}
\hline Year & 2005 & 2006 & 2007 & 2008 & 2009 & 2010 & 2011 & 2012 & 2013 & 2014 & 2015 & 2016 & 2017 & 2018 \\
\hline Jiangsu & 0.178 & 0.152 & 0.134 & 0.138 & 0.129 & 0.144 & 0.122 & 0.094 & 0.088 & 0.057 & 0.078 & 0.065 & 0.093 & 0.063 \\
Shandong & 0.096 & 0.127 & 0.141 & 0.148 & 0.158 & 0.166 & 0.179 & 0.174 & 0.163 & 0.155 & 0.151 & 0.152 & 0.165 & 0.099 \\
Anhui & 0.128 & 0.124 & 0.145 & 0.121 & 0.120 & 0.139 & 0.158 & 0.141 & 0.142 & 0.143 & 0.150 & 0.135 & 0.120 & 0.103 \\
Henan & 0.129 & 0.104 & 0.064 & 0.069 & 0.071 & 0.083 & 0.100 & 0.089 & 0.111 & 0.084 & 0.112 & 0.134 & 0.129 & 0.153 \\
Economic belt & 0.215 & 0.207 & 0.240 & 0.230 & 0.211 & 0.240 & 0.240 & 0.218 & 0.214 & 0.196 & 0.202 & 0.185 & 0.175 & 0.161 \\
\hline
\end{tabular}

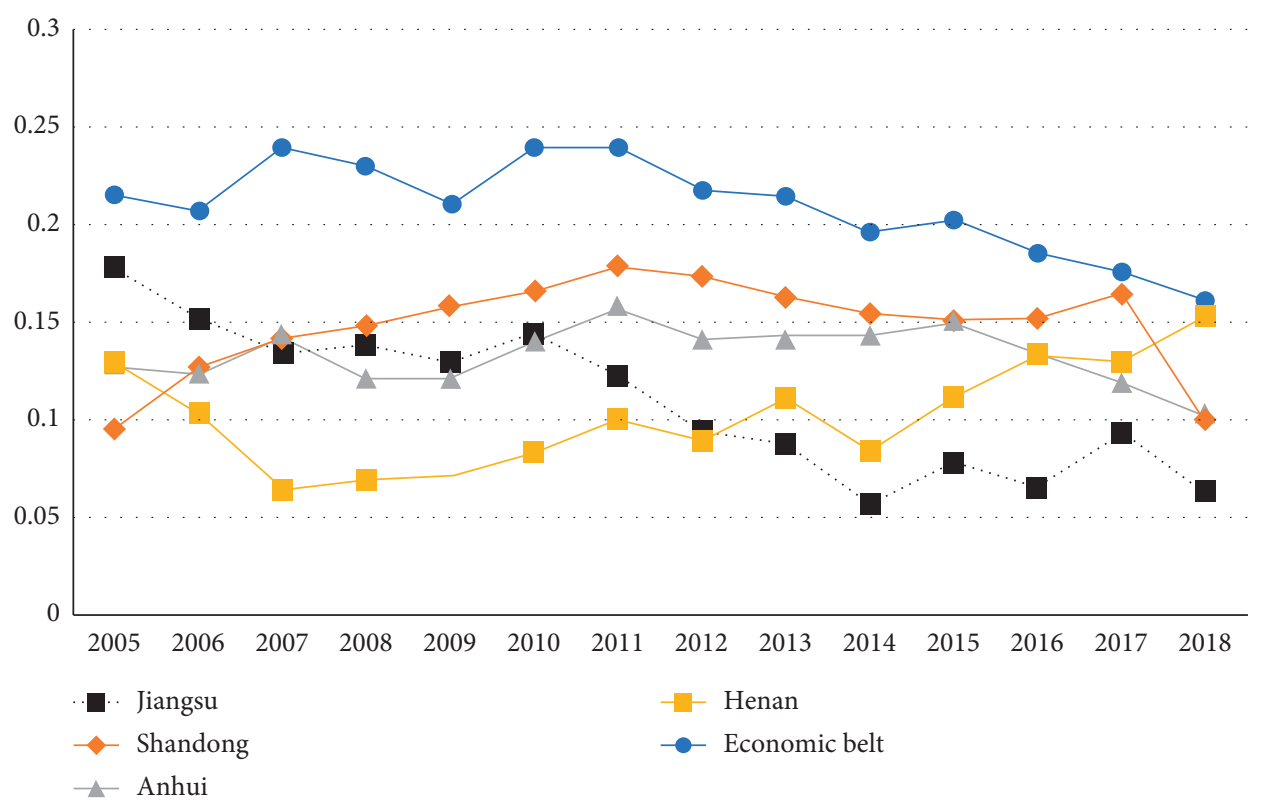

Figure 8: Value trend of comprehensive competitiveness of cities in Huaihe eco-economic belt from 2005 to 2018.

national policies and local governments, the preference of resource allocation and capital utilization is that the superior resources are relatively concentrated in the cities of the relatively developed provinces of the Huaihe River ecological economic belt. Jiangsu Province is in the Huaihe River ecological economic belt, which belongs to the concentration of superior resources, and its economic development is in the leading position. The competitiveness gap of cities in Jiangsu Province is gradually narrowing. However, there is a time lag effect of resource and industrial agglomeration to promote urban development in Shandong, Anhui, and Henan Provinces, which shows the differences among regional cities. Therefore, since the outline of Huaihe ecological economic belt was put forward, all-round and multilink policy support should be provided in terms of funds, technology, and talents. Local governments should seize the opportunity to promote the construction of green development system and mechanism, actively guide enterprises to develop knowledge-intensive industries, accelerate the upgrading of technological level, and actively promote the transformation and upgrading of industrial structure, so as to pass more and more efforts, Fang made joint efforts to improve the competitiveness of cities in the Huaihe River ecological economic belt. Figure 8 more intuitively reflects the trend of the $\alpha$-value of urban competitiveness in Northeast China from 2005 to 2018.
6.2. $\beta$-Convergence Test. $\alpha$-convergence can only show whether the urban competitiveness converges at this level, but it cannot judge whether the cities with lower initial competitiveness can catch up with the growth trend of urban competitiveness with higher initial competitiveness. Therefore, it is necessary to further test the $\beta$-convergence.

$\beta$-convergence method means that regions with low initial per capita income have higher per capita income growth rate than those with high initial per capita income. Different from $\alpha$-convergence, $\beta$-convergence emphasizes convergence on growth rate. Based on the neoclassical economic growth theory, the convergence model constructed in this paper is as follows:

$$
y_{t}-y_{t-1}=a+b y_{t-1}+\varepsilon_{t} .
$$

where $y_{t-1}$ represents the level of urban competitiveness of the previous year, $y_{t}$ represents the level of urban competitiveness of the following year, $a$ is a constant term, $b$ is a convergence coefficient, and $\varepsilon_{t}$ is a random error term. If $b<0$, it means that there is $\beta$-convergence, and the greater the absolute value of $b$, the stronger the convergence.

Through the $\beta$-convergence model, the following regression results can be obtained, as shown in Table 6 .

From the result of $\beta$-convergence, the convergence coefficient $b$ of urban resilience level of economic belt, Jiangsu Province, Shandong Province, and Henan 
TABLE 6: $\beta$-convergence test of urban competitiveness in Huaihe eco-economic belt.

\begin{tabular}{lcccc}
\hline Name & Economic belt & Jiangsu & Shandong & Anhui \\
\hline Coefficient b & -0.450 & $-1.1334^{* * *}$ & $-0.387^{*}$ & 0.060 \\
Constant term a & 0.172 & $0.608^{* * *}$ & 0.152 & -0.282 \\
After adjustment $R^{2}$ & 0.240 & 0.507 & 0.165 & -0.013 \\
F & 3.47 & 13.33 & 3.37 & -0.072 \\
\hline
\end{tabular}

Province are all less than 0 , and only Jiangsu Province has passed the significance test, which shows that Jiangsu Province shows $\beta$-convergence, while the economic belt in Shandong Province, Anhui Province, and Henan Province shows no signs of convergence or divergence. Specifically, with the economic radiation of the provincial capital cities and central cities in Jiangsu Province, some cities with low initial urban competitiveness have higher growth rate of urban competitiveness than those with high initial urban competitiveness. Taking Suqian City as a typical representative, before 2007, Suqian City's competitiveness level was behind 13 but gradually stabilized within 10 after 2008. The economic belt includes Shandong Province, Anhui Province, Shandong Province, and Henan Province. Due to the relatively closed geographical position, the stagnant development of regional leading industries and the difficulties in the transformation and upgrading of industrial structure, the urban development is backward and the growth rate of relative urban competitiveness level is far less than that of other cities.

\section{Conclusions and Policy Recommendations}

This paper constructs the evaluation index system of urban competitiveness of Huaihe River ecological economic belt, calculates the final evaluation value, and analyzes the actual situation. Finally, through exploring the potential relationship between urban competitiveness and economic growth and the spatial correlation of regional economic growth, it puts forward relevant suggestions.

The comprehensive score of the entropy method shows that, from 2005 to 2017, due to the influence of the economic situation radiation of Jiangsu from the south of Jiangsu Province to the middle of Jiangsu Province and then to the north of Jiangsu Province, Yangzhou and Taizhou City have been ranked in the top two in terms of urban competitiveness in recent years, but they have declined to a certain extent in 2018. In general, the cities with high quality and high level of development in Huaihe ecological economic belt are all cities in Jiangsu Province, so we should give full play to the role of Jiangsu Province and other provinces in economic radiation and promote the economic development of other provinces and cities. In recent years, with the rise of Anhui cities, Bengbu City, as the transportation hub of Huaihe River ecological economic belt, Chuzhou City is adjacent to Nanjing City, the capital of Jiangsu Province. In recent years, the comprehensive ranking of Bengbu City has risen sharply. Their huge development potential and prosperous development force will undoubtedly boost the good development of Huaihe ecological economic belt.
The results of spatial correlation of urban competitiveness show that there is a positive spatial autocorrelation between the level of urban competitiveness and the spatial distribution of Huaihe River region, and this correlation is increasing with the passage of time, but the spatial correlation between cities is generally low, and there is still a lot of room for improvement in economic cooperation. The specific suggestions are that the regional cities should optimize the industrial layout, take the innovation and development as the guide, pay attention to the ecological environment protection, and form the industrial structure, growth mode, and consumption mode of saving resources and protecting the environment. To promote the economic development of regional cities, it is necessary to coordinate the development of urbanization and industrialization, promote the integration of industry and city, and optimize the spatial layout. According to the characteristics of Huaihe River Basin, the economic radiation driving effect under the priority development mode of "downstream midstream upstream" is formed.

The results of spatial convergence of urban competitiveness show that the level of urban competitiveness of Jiangsu Province presents $\alpha$-convergence and $\beta$-convergence, while the other provinces of economic belt do not show obvious $\alpha$-convergence and $\beta$-convergence trend. The gap between the level of urban competitiveness in Jiangsu Province is constantly narrowing. The urban development of other provinces in Huaihe ecological economic belt has a time lag effect, and there are differences in the level of urban competitiveness. In recent years, the comprehensive level of urban competitiveness of Yangzhou, Yancheng, and Xuzhou is relatively high. Due to their own advantages (such as strong provincial economic environment and convenient transportation), the level of urban competitiveness will be developed continuously. The economic growth brought by these advantages will also promote the improvement of urban competitiveness. However, cities with low competitiveness and poor economic development will be faced with the following problems facing sustained stagnation of development. One belt, one road, the Yangtze River economic belt, the Central Plains Economic Zone, and the Wanjiang economic belt will be integrated into the city's strategic linkage with the Huaihe eco-economic belt city.

The implementation of the development plan of Huaihe ecological economic belt is to give full play to the c-position role of high-quality city competitiveness on the premise of maintaining good green development and form an impact system of urban competitiveness with economic strength as the leading factor, social services as the support, cultural innovation, opening up, and ecological environment as auxiliary support. 
Through the construction and analysis of the urban competitiveness index system of the Huaihe River EcoEconomic Zone under high-quality development, this study is helpful to understand and grasp the current development and existing problems of the Huaihe River Eco-Economic Zone city group and further improve the economy of the economic zone. The development level and quality of the policy recommendations and basis are also of certain reference value for the economic development of other regions in my country. Due to the limitation of data, the research on urban competitiveness in this article is mainly reflected in indicators such as economy, environment, innovation, and quality of life. However, there are many other direct and indirect indicators of urban competitiveness to be studied. Future research should increase sample indicators, refine sample areas, expand the sample range of county-level cities in the Huaihe River eco-economic belt, and deeply analyze the urban competitiveness of different types of cities at different development stages. Finally, it is worth noting that, due to the limitations of the author's knowledge and the lack of statistical data, this study has limitations in evaluating the competitiveness of cities in the Huaihe eco-economic belt. Different index evaluation systems, sample data, or sample time periods may lead to different evaluation results.

\section{Data Availability}

The data are from "China Urban Statistical Yearbook," as well as the calendar yearbook of various provinces and cities, statistical yearbook, and statistical bulletin of each city. Some index values are sorted out and calculated on the basis of the statistical yearbook.

\section{Conflicts of Interest}

The authors declare that there are no conflicts of interest regarding the publication of this paper.

\section{Acknowledgments}

This study was funded by Humanities and Social Sciences Research Major Project of Education Department of Anhui Province (SK2017A0452), Anhui Philosophy Social Sciences Planning Project (AHSKY2017D11), and Provincial Foundation for Excellent Young Talents of Colleges and Universities of Anhui Province (gxgwfx2018030). This study was also supported by the Anhui Department of Education Teaching and Research Fund Project (2018jyxm1305), Teaching and Research Project of Anhui University of Finance and Economics (acjyyb2020011), and Major Project of Anhui University of Finance and Economics (ACKY1703ZDA).

\section{References}

[1] F. Lever and W. Turok, "Competitive cities: introduction to the review," Urban Studies, vol. 36, no. 5-6, pp. 791-793, 1999.

[2] E. J. Malecki, "Hard and soft networks for urban competitiveness," Urban Studies, vol. 39, no. 5-6, pp. 929-945, 2002.
[3] I. Turok, "Cities, regions and competitiveness," Regional Studies, vol. 38, no. 9, pp. 1069-1083, 2004.

[4] S. Iyer, M. Kitson, and B. Toh, "Social capital, economic growth and regional development," Regional Studies, vol. 39, no. 8, pp. 1015-1040, 2005.

[5] F. Gundersen, O. Langeland, and J. Aarhaug, "Work place location, transport and urban competitiveness: the Oslo case," Transportation Research Procedia, vol. 26, pp. 196-206, 2017.

[6] Y. M. Ning and L. Z. Tang, "Concept and index system of urban competitiveness," Modern City Research (of China), vol. 3, pp. 19-22, 2001.

[7] P. F. Ni, "The analysis paradigm and conceptual framework of China's urban competitiveness," Economic Developments (of China), vol. 6, pp. 14-18, 2001.

[8] P. R. Krugman, "Making sense of the competitiveness debate," Oxford Review of Economic Policy, vol. 12, no. 2, pp. 17-25, 1996.

[9] M. Mlachila, R. Tapsoba, and S. J. A. Tapsoba, "A quality of growth index for developing countries: a proposal," Social Indicators Research, vol. 134, no. 2, pp. 675-710, 2017.

[10] J. Qi, "Fiscal expenditure incentives, spatial correlation and quality of economic growth: evidence from a Chinese province," International Journal of Business and Management, vol. 11, no. 7, pp. 191-201, 2016.

[11] Y. Y. Li, "An empirical study on the quality of economic development: Jiangsu's experience-based on the analysis of the quality index system of economic development," Finance and Trade Economics (of China), vol. 8, pp. 113-118, 2008.

[12] X. J. Chao and B. P. Ren, "Analysis of time series changes and regional differences of China's economic growth quality," Economic Research (of China), vol. 46, no. 4, pp. 26-40, 2011.

[13] Z. H. Li, "A study on urban competitiveness based on the perspective of city networks-taking the guangdong-Hong Kong-Macao Bay area as an example," World Scientific Research Journal, vol. 6, no. 4, pp. 282-292, 2020.

[14] J. S. Liu and X. J. Li, "Measurement of China's urban competitiveness index and its influencing factors: an Empirical Study Based on panel data of 30 cities in China from 1990 to 2012," Financial Science (of China), vol. 8, pp. 92-100, 2013.

[15] M. L. Tian and S. M. Fang, "Evaluation and spatiotemporal evolution of competitiveness of central cities in Hanjiang River Basin," Statistics and Decision Making (of China), vol. 9, pp. 103-106, 2016.

[16] X. L. Yang and P. F. Ni, "The origin and development of urban sustainable competitiveness," Economic Trends (of China), vol. 9, pp. 96-110, 2017.

[17] Y. He, "Analysis on influencing factors of urban competitiveness in Western China from the perspective of ecological economy," Ecological Economy (of China), vol. 34, no. 7, pp. 99-103, 2018.

[18] P. Liu and J. Song, "Research on the application of urban competitiveness evaluation in the new urbanization of Beijing Tianjin Hebei," Journal of Hebei University of Economics and Trade (of China), vol. 40, no. 2, pp. 65-72, 2019.

[19] X. H. Li, "Research on comprehensive evaluation of economic and social development performance from the perspective of "five in one" general layout-Taking China's "Twelfth Five Year Plan" period as an example," Science and Technology Management Research (of China), vol. 39, no. 6, pp. 63-71, 2019.

[20] R. J. Rogerson, "Quality of life and city competitiveness," Urban Studies, vol. 36, no. 5-6, pp. 969-985, 1999. 
[21] S. Singhal, S. Mcgreal, and J. Berry, "An evaluative model for city competitiveness: application to UK cities," Land Use Policy, vol. 30, no. 1, pp. 214-222, 2013.

[22] F. Jamali, S. Rosteai, and M. Y. Gharavi, "An assessment of the causal model of effective metrics on urban competitiveness using a fuzzy DEMATEL approach," Urban Economics and Management, vol. 6, no. 23, pp. 145-162, 2018.

[23] I. Begg, "Cities and competitiveness," Urban Studies, vol. 36, no. 5-6, pp. 795-809, 1999.

[24] P. K. Kresl and B. Singh, "Competitiveness and the urban economy: twenty-four large US metropolitan areas," Urban Studies, vol. 36, no. 5-6, pp. 1017-1027, 1999.

[25] B. Gardiner, R. Martin, and P. Tyler, "Competitiveness, productivity and economic growth across the European regions," Regional Studies, vol. 38, pp. 1037-1059, 2004.

[26] N. Esmaeilpoorarabi, T. Yigitcanlar, and M. Guaralda, "Place quality and urban competitiveness symbiosis? A position paper," International Journal of Knowledge-Based Development, vol. 7, no. 1, pp. 4-21, 2016.

[27] F. Matos, V. M. Vairinhos, R. P. Dameri, and S. Durst, "Increasing smart city competitiveness and sustainability through managing structural capital," Journal of Intellectual Capital, vol. 18, no. 3, pp. 693-707, 2017.

[28] P. O'Neill, E. Knight, and D. Wójcik, "Australia's shifting global engagement: the stuttering rise of financial services and city-based competitiveness," Australian Geographer, vol. 49, no. 3, pp. 349-364, 2018.

[29] M. L. Song and Q. J. Xie, "Evaluation of urban competitiveness of the Huaihe River eco-economic belt based on dynamic factor analysis," Computational Economics, vol. 12, pp. 1-25, 2019.

[30] G. X. Mao, H. T. Chen, and X. F. Hu, "Research on industrial coordinated development of Huaihe ecological economic belt," Journal of Jiangsu Normal University (of China), vol. 33, no. 7, pp. 1-7+93, 2015.

[31] C. W. Ma and N. Peng, "Evaluation of the development level of ecological economy in the Huaihe River eco-economy zone," Journal of Zhongyuan Institute of Technology (of China), vol. 29, no. 2, pp. 41-48, 2018.

[32] Z. A. Ren and B. Y. Liu, "Spatial and temporal differences and influencing factors of agricultural water resources green efficiency in Huaihe river ecological economic belt," Resource Development and Market (of China), vol. 35, no. 7, pp. 929-934+941, 2019.

[33] J. W. Zhou, Z. Y. Jiang, and F. Li, "Study on the development and influencing factors of green economy in the Yangtze River economic belt," Ecological Economy (of China), vol. 34, no. 12, pp. $47-53+69,2018$.

[34] Z. A. Ren, Y. Miao, and B. Y. Xu, "Ecological efficiency evaluation of Huaihe River eco economic belt based on three stage DEA model," Journal of Tonghua Normal University (of China), vol. 40, no. 5, pp. 46-51, 2019.

[35] J. W. Sun and S. C. Yi, "Research on ways to promote the high-quality development of the Huaihe River eco-economic belt," Finance and Trade Research (of China), vol. 31, no. 3, pp. $43-48,2020$.

[36] J. C. Li, L. M. Shi, and A. T. Xu, "Discussion on evaluation index system of high quality development," Statistical Research (of China), vol. 36, no. 1, pp. 4-14, 2019. 